\title{
Effect of captopril on renal function in patients with congestive heart failure
}

\author{
GORDON L PIERPONT, GARY S FRANCIS, JAY N COHN
}

From the Division of Cardiology, University of Minnesota Hospitals and Minneapolis Veterans Administration Medical Center, Minneapolis, Minnesota, USA

SUMMARY Angiotensin converting enzyme inhibitors can improve haemodynamics in patients with congestive heart failure and may enhance sodium excretion in hypertensive patients. In a metabolic unit we assessed the effects of one of these agents on renal function in nine patients with stable New York Heart Association functional class 3 or 4 congestive heart failure. Single blinded, the patients received placebo for three days, 25 to $100 \mathrm{mg}$ of captopril three times a day for three days, and three more days of placebo. Mean blood pressure decreased during captopril, with little change in heart rate or respiration. Serum urea was slightly higher during captopril administration. The mean change in creatinine clearance during captopril was insignificant, but it decreased more than $25 \%$ in three of nine patients. Decreases in creatinine clearance correlated with lower blood pressure during captopril and were most obvious in patients with high baseline plasma renin activity. Urine output and both sodium and potassium excretion decreased during captopril. Thus captopril failed to improve natriuresis in patients with congestive heart failure and close monitoring of kidney function is necessary when using this agent in patients with congestive heart failure, particularly when blood pressure falls to lower levels.

The renin angiotensin system has been postulated to play an important role in sustaining the high peripheral vascular resistance that is characteristic of severe congestive heart failure. ${ }^{12}$ This hypothesis has been supported by demonstration of haemodynamic and clinical improvement when angiotensin converting enzyme inhibitors are used as vasodilator treatment for patients with congestive heart failure. ${ }^{1-5}$ Though the low cardiac output of patients with congestive heart failure improves with angiotensin converting enzyme inhibition, little is known about the regional distribution of the improved blood flow. This study was therefore designed to assess the effects of the renin angiotensin converting enzyme inhibitor, captopril, on renal function in patients with congestive heart failure.

\section{Methods}

Informed consent was obtained from 11 male patients with New York Heart Association functional class 3 or 4 heart failure, that is who were symptomatic either at rest (class 4) or with minimal exertion (class 3). Five of the patients were class 4 and six were in class Received for publication 30 June 1981
3. The patients ranged in age from 48 to 83 years, with an average age of 59.9 years. Five of the patients were assessed clinically to have dilated cardiomyopathy while in the remainder, heart failure was the result of ischaemic heart disease. Patients were excluded from the study for: insulin-dependent diabetes mellitus, severe pulmonary disease $\left(\mathrm{PCO}_{2}<50\right.$ $\mathrm{mmHg}$ or $\mathrm{PCO}_{2}>50 \mathrm{mmHg}$ ), renal insufficiency (serum urea $>14.3 \mathrm{mmol} / \mathrm{l}$ ) (BUN $740 \mathrm{mg} / \mathrm{dl}$ ) or creatinine $>176.8 \mu \mathrm{mol} / \mathrm{l}(2 \mathrm{mg} / 100 \mathrm{ml})$ ), abnormal serum electrolytes, angina requiring nitrate treatment, myocardial infarction within the past three months, significant primary heart valve disease, or hypertension requiring non-diuretic antihypertensive agents.

All patients were felt to be clinically stable with a steady body weight when admitted to the special diagnostic and treatment unit (SDTU) of the Minneapolis Veterans Administration Medical Center where the study was performed. Five patients had previously been receiving vasodilators (isosorbide dinitrate and/or hydralazine), but these were stopped more than 24 hours before entry into the study. Every patient was receiving both a diuretic and digitalis at the time of admission. These medications, as well as 
any other medication the patient was taking regularly (excluding vasodilators), were continued throughout the study period. All medication remained at a constant dose with the exception of two patients in whom potassium supplementation was decreased during the study because of rising serum potassium levels.

On admission to SDTU a dietary history was taken by a nutritionist and a diet constructed to match the usual sodium intake for each patient. Sodium and fluid intake were kept as constant as was practically attainable for the duration of the study, and patients were allowed their normal level of activity. Supine blood pressure, heart rate, respirations, and temperature were monitored four times daily, and the patients were weighed twice daily. Mean blood pressure was calculated as diastolic pressure plus one-third of the pulse pressure.

On the day after admission to SDTU the patients were given a trial dose of $25 \mathrm{mg}$ oral captopril, and their vital signs were recorded every 15 minutes until they returned to control levels. If the patients tolerated the drug well and responded with a decrease in blood pressure, the dose of captopril used was 25 $\mathrm{mg}$ three times daily. In two patients $25 \mathrm{mg}$ captopril failed to affect blood pressure appreciably, and the dose subsequently used in these two patients was 100 mg orally three times a day.

Two days later the procedure was begun with three periods of three days each for a total of nine days. The first period consisted of three days of placebo administration (one tablet three times a day). This was followed by three days of captopril treatment ( 25 or $100 \mathrm{mg}$ three times a day), then another placebo period. The investigators, but not the patients, knew when active drug was being given. Each morning blood was drawn for determination of serum urea, creatinine, glucose, sodium, chloride, total bicarbonate, potassium, and osmolality. Blood was drawn on the third day of each period in the early morning with the patient supine and analysed for plasma renin activity. Total urine output was collected at eight hour intervals throughout the study and analysed for creatinine, potassium, and sodium. Twenty-four hour creatinine clearance was calculated by combining the results of the three daily urine collections.

Average daily values for each variable studied were analysed using analysis of variance for repeated measures on the same elements. The null hypothesis tested was that there is no difference between the daily values obtained during the three days of captopril compared with the six days of placebo, and differences were considered statistically significant for $p$ values less than 0.05 . The data were also examined for changes within a given study period or between the two placebo periods.

\section{Results}

Nine of the 11 patients who entered the study were able to complete the procedure. One patient became symptomatically hypotensive with the test dose of captopril $(25 \mathrm{mg})$. His systolic blood pressure decreased transiently from a control level of $98 \mathrm{mmHg}$ to a minimum of $64 \mathrm{mmHg}$ and he had symptoms of dizziness, light-headedness, and weakness, which required the procedure to be discontinued. Another patient tolerated the initial test dose of captopril well but was withdrawn during the initial placebo period when he became clinically unstable and developed a new pulmonary infiltrate on his chest $x$-ray. Thus the following data are from the nine patients who completed the procedure.

Three of the patients had no change in their symptoms during the study while one patient noted gradual improvement during his SDTU stay which he could not relate to any change in medication. Three patients noted improvement in symptoms, such as "breathing easier" and "more get up and go," which they could specifically relate to the three days during which they received captopril. Two patients noted slight dizziness associated with the captopril. As noted in the methods section, two patients required a decrease in potassium supplementation because of high serum levels, one during the captopril period and one during the first placebo period.

The Table presents the average daily values $( \pm$ standard deviation) for the more pertinent variables studied. The $p$ values are given for testing the null hypothesis that there is no difference between the values during the three days of captopril compared with those during the six days of placebo. It can be seen that mean blood pressure during captopril was $7.9 \pm 3.9 \mathrm{mmHg}$, lower than the average of the two placebo periods. The lower mean blood pressure was the result of a decrease in both systolic and diastolic blood pressure (not shown in the Table). Systolic blood pressure decreased an average of $10 \cdot 3 \pm 4 \cdot 5$ $\mathrm{mmHg}(\mathrm{p}<0.001)$ and diastolic blood pressure decreased $6.8 \pm 5 \cdot 1 \mathrm{mmHg}(\mathrm{p}<0.001)$.

There was no change in respiratory rate (Table), but a slight decrease in heart rate averaging $2 \cdot 8 \pm 4 \cdot 6$ beats/min occurred during captopril $(p<0.05)$. This change in heart rate was mainly because of a decrease between the first placebo period and the captopril period, as the heart rate did not return to control after stopping captopril. Thus, it is not clear that this small and clinically insignificant change in heart rate is the result of captopril.

The average decrase in daily urine output during captopril was $300 \pm 460 \mathrm{ml} / 24 \mathrm{~h}(\mathrm{p}<0.01)$. Consistent with the decrease in urine output, daily weight increased during captopril. The average weight 
Table Mean values $( \pm S D)$ for all nine patients during each of nine days of study. $p$ values are given for testing null hypothesis that there is no difference between values during three days of captopril compared with six placebo days

\begin{tabular}{|c|c|c|c|c|c|c|c|c|c|c|}
\hline \multirow[b]{2}{*}{ Day } & \multicolumn{3}{|c|}{ Placebo } & \multicolumn{3}{|c|}{ Captopril } & \multicolumn{3}{|c|}{ Placebo } & \multirow[t]{2}{*}{ Probability } \\
\hline & 1 & 2 & 3 & 4 & 5 & 6 & 7 & 8 & 9 & \\
\hline $\mathrm{BP}(\mathrm{mmHg})$ & $96 \cdot 4 \pm 8 \cdot 7$ & $94 \cdot 8 \pm 9 \cdot 4$ & $95 \cdot 0 \pm 8 \cdot 8$ & $84 \cdot 5 \pm 9 \cdot 7$ & $85 \cdot 6 \pm 9 \cdot 1$ & $87 \cdot 2 \pm 8 \cdot 8$ & $90 \cdot 1 \pm 8 \cdot 1$ & $93 \cdot 8 \pm 9 \cdot 6$ & $91 \cdot 6 \pm 8 \cdot 1$ & $\mathrm{p}<0.001$ \\
\hline Resp/min & $22 \cdot 4 \pm 2 \cdot 3$ & $23.2 \pm 2.9$ & $22 \cdot 9 \pm 3 \cdot 1$ & $22 \cdot 1 \pm 2 \cdot 7$ & $22 \cdot 4 \pm 2 \cdot 4$ & $22 \cdot 5 \pm 1 \cdot 8$ & $22 \cdot 6 \pm 2 \cdot 3$ & $22 \cdot 8 \pm 2 \cdot 5$ & $22 \cdot 3 \pm 2 \cdot 4$ & NS \\
\hline HR (beats/min) & $80 \cdot 8 \pm 15 \cdot 2$ & $84 \cdot 5 \pm 15 \cdot 5$ & $79 \cdot 7 \pm 12 \cdot 7$ & $74 \cdot 5 \pm 8 \cdot 4$ & $76 \cdot 3 \pm 8 \cdot 0$ & $80 \cdot 0 \pm 12 \cdot 7$ & $77 \cdot 1 \pm 12 \cdot 4$ & $78 \cdot 3 \pm 11 \cdot 6$ & $77 \cdot 3 \pm 10 \cdot 8$ & $\mathrm{p}<0.05$ \\
\hline Urine vol $(\mathrm{ml} / 24 \mathrm{~h})$ & $2185 \pm 1207$ & $2200 \pm 949$ & $2230 \pm 1138$ & $1958 \pm 1081$ & $1876 \pm 894$ & $2123 \pm 1206$ & $2613 \pm 1623$ & $2372 \pm 1287$ & $2130 \pm 1248$ & $\mathrm{p}<0.01$ \\
\hline Weight (kg) & $87 \cdot 3 \pm 18 \cdot 9$ & $87 \cdot 0 \pm 18 \cdot 7$ & $87 \cdot 1 \pm 18 \cdot 7$ & $87 \cdot 3 \pm 18 \cdot 8$ & $87 \cdot 3 \pm 18 \cdot 8$ & $87 \cdot 2 \pm 18 \cdot 8$ & $86 \cdot 7 \pm 18 \cdot 4$ & $86 \cdot 4 \pm 18 \cdot 4$ & $86 \cdot 5 \pm 18 \cdot 5$ & $\mathrm{p}<0.005$ \\
\hline \multicolumn{11}{|l|}{ Sodium excretion } \\
\hline \multicolumn{11}{|l|}{ Potassium excretion } \\
\hline$(\mathrm{mmol} / 24 \mathrm{~h})$ & $126 \pm 76$ & $135 \pm 75$ & $122 \pm 76$ & $106 \pm 55$ & $108 \pm 61$ & $114 \pm 67$ & $145 \pm 84$ & $123 \pm 70$ & $129 \pm 81$ & $\mathrm{p}<0.005$ \\
\hline Sodium bal (mg/24 h) & $-254 \pm 963$ & $-198 \pm 1105$ & $-276 \pm 847$ & $277 \pm 642$ & $277 \pm 366$ & $-10 \pm 570$ & $-234 \pm 818$ & $-193 \pm 779$ & $177 \pm 668$ & $\mathrm{p}<0.05$ \\
\hline Sodium $(\mathrm{mmol} / \mathrm{l})$ & $141 \pm 4$ & $138 \pm 3$ & $139 \pm 3$ & $138 \pm 2$ & $139 \pm 3$ & $138 \pm 3$ & $139 \pm 4$ & $140 \pm 4$ & $140 \pm 3$ & $\mathrm{p}<0.05$ \\
\hline Potassium $(\mathrm{mmol} / \mathrm{l})$ & $4 \cdot 4 \pm 0 \cdot 6$ & $4 \cdot 5 \pm 0 \cdot 8$ & $4 \cdot 3 \pm 0.8$ & $4 \cdot 5 \pm 0.8$ & $4 \cdot 7 \pm 1 \cdot 0$ & $4 \cdot 6 \pm 0 \cdot 7$ & $4 \cdot 4 \pm 0.6$ & $4 \cdot 4 \pm 0 \cdot 5$ & $4.4 \pm 0.6$ & $p<0.05$ \\
\hline Creatinine $(\mu \mathrm{mol} / \mathrm{l})$ & $114 \cdot 9 \pm 26 \cdot 5$ & $106 \cdot 1 \pm 26 \cdot 5$ & $106 \cdot 1 \pm 17 \cdot 7$ & $114 \cdot 9 \pm 26 \cdot 5$ & $114.9 \pm 26 \cdot 5$ & $114 \cdot 9 \pm 35 \cdot 4$ & $106 \cdot 1 \pm 26 \cdot 5$ & $114 \cdot 9 \pm 26 \cdot 5$ & $106 \cdot 1 \pm 26 \cdot 6$ & NS \\
\hline \multicolumn{11}{|l|}{ Creatinine clearance } \\
\hline$(\mathrm{ml} / \mathrm{min})$ & $69 \cdot 5 \pm 29 \cdot 3$ & $80 \cdot 4 \pm 42 \cdot 3$ & $73 \cdot 8 \pm 43 \cdot 4$ & $70 \cdot 1 \pm 28 \cdot 0$ & $72 \cdot 1 \pm 39 \cdot 1$ & $67 \cdot 2 \pm 36 \cdot 8$ & $74 \cdot 1 \pm 35 \cdot 5$ & $73 \cdot 0 \pm 36 \cdot 4$ & $76 \cdot 0 \pm 35 \cdot 1$ & NS \\
\hline
\end{tabular}

increase was only $0.45 \pm 0.76 \mathrm{~kg}$ but since it increased in almost every patient, this was significant $(\mathrm{p}<0.005)$.

Both sodium and potassium excretion decreased during captopril administration. On the average, sodium excretion was lower by $13 \cdot 1 \pm 28 \cdot 3 \mathrm{mmol} / 24 \mathrm{~h}$ $(\mathrm{p}<0.05)$, while potassium excretion was lower by $20.8 \pm 23.6 \mathrm{mmol} / 24 \mathrm{~h}(\mathrm{p}<0.005)$. This was associated with an increase in serum potassium during captopril of $0.2 \mathrm{mmol} / \mathrm{l}(\mathrm{p}<0.05)$, but serum sodium was $1 \cdot 1 \pm 1.9 \mathrm{mmol} / 1$ lower during captopril than during placebo $(\mathrm{p}<0.05)$.

As noted in the Table, neither serum creatinine nor creatinine clearance changed significantly. Serum urea, however, was on the average $1.14 \pm 1.36 \mathrm{mmol} / \mathrm{l}$ higher during captopril than placebo $(p<0.05)$. Data not presented in the Table include serum bicarbonate, chloride, glucose, and osmolality, none of which changed significantly.

In order to determine if the patients were indeed stable as they began the study, we tested the null hypothesis that there is no difference between the daily averages obtained for each variable during the first three days of the study (that is during the first placebo period). Of all the variables studied, statistically significant variations during this period were found only for heart rate, serum sodium and creatinine, and creatinine clearance. It can be seen in the Table that both heart rate and creatinine clearance were slightly higher during day 2 than days 1 and 3 . Serum sodium was higher on day 1 than days 2 and 3 while serum creatinine was lower on day 2 than days 1 and 3. Thus, there was no clear trend or consistent change in the few variables where statistically significant variation did occur during the first placebo period.

In order to see if there was any progressive accumulative effect of captopril, or development of tolerance, we tested the null hypothesis that there is no difference between the data during each of the three days of captopril treatment. Of the variables studied, the only significant difference during captopril occurred with heart rate $(p<0.01)$ which progressively increased from day 4 to day 6 . Since the magnitude of the changes was small, and since all the other variables were stable, it is unlikely that this variation is clinically important.

It is possible that the effects of captopril might continue beyond the sixth day of the study or that a rebound response may occur when captopril is stopped. To check these possibilities, we tested the null hypothesis that there is no difference between day 7,8 , and 9 (that is, during the second placebo period). The urine output, sodium excretion, and potassium excretion during day 7 were significantly higher $(\mathrm{p}<0.01, \mathrm{p}<0.05$, and $\mathrm{p}<0.05$, respectively) than days 8 and 9 (see Table). This suggests the possibility of a rebound phenomenon occurring in the kidney, but there was no other evidence of this, though mean and systolic blood pressure did vary significantly $(\mathrm{p}<0.05$ and $\mathrm{p}<0.001)$ during days 7,8 , and 9, largely as a result of a higher pressure on day 8 than on days 7 and 9. Apart from a significantly lower serum sodium and chloride on day 7 compared with days 8 and $9(p<0.05$ and $p<0.01)$ other variables showed no significant change during the second placebo period.

Plasma renin activity was higher during captopril 
than during the placebo periods, changing from $12 \cdot 7 \pm 22 \cdot 3 \mathrm{ng} / \mathrm{ml}$ per $\mathrm{h}$ during the first placebo period to $16 \cdot 6 \pm 19 \cdot 2 \mathrm{ng} / \mathrm{ml}$ per $\mathrm{h}$ during captopril, and $12 \cdot 6 \pm 22 \cdot 7 \mathrm{ng} / \mathrm{ml}$ per $\mathrm{h}$ during the second placebo period $(\mathrm{p}<0 \cdot 01)$.

\section{Discussion}

The results of this study indicate that detrimental effects on renal function can occur when patients with congestive heart failure are treated with captopril. Fluid and electrolyte retention were evident by the increase in daily weight and the decrease in urine volume and sodium and potassium excretion during captopril. Despite the decrease in sodium excretion and the more positive sodium balance during captopril, there was a slight decrease in serum sodium concentration, indicating relatively more water than sodium retention. Maslowski et al. ${ }^{6}$ have also reported a fall in serum sodium in these circumstances.

There are few previous data available on the renal effects of angiotensin converting enzyme inhibitors when used to treat congestive heart failure. Dzau $e t$ $a .^{5}$ studied long term effects of captopril in eight patients with congestive heart failure. They obtained pre- and post-therapy studies of para-aminohippurate clearance in five of the patients and creatinine clearances in six patients. Both para-aminohippurate and creatinine clearance increased five to seven days after the onset of captopril treatment. They reported a decrease in serum urea nitrogen and creatinine with captopril consistent with an improved glomerular filtration rate and renal plasma flow. Serum sodium increased from abnormally low values to normal values with captopril in their study, whereas in our study all patients had normal serum electrolytes at entry. In contrast, Sharpe et al. ${ }^{7}$ noted no change in serum creatinine or in protein excretion in 11 class 3 or 4 patients given chronic captopril treatment. Maslowski et al. ${ }^{6}$ found, as we did, potassium retention in five patients during four days of captopril, and this occurred at the same time as clinical and haemodynamic improvement.

In patients with hypertension, the effects of angiotensin converting enzyme inhibitors on renal function and electrolyte balance have also been variable. Hollenberg et al. ${ }^{8}$ found an increase in creatinine clearance despite a decrease in blood pressure when teprotide was administered. Atlas et al. ${ }^{9}$ reported natriuresis, potassium retention, and reduced aldosterone secretion in 23 hypertensives given captopril. On the other hand, Atkinson et al. ${ }^{10}$ found no significant change in exchangeable sodium or total body potassium in eight patients given captopril, and sodium excretion increased minimally during captopril in 22 hypertensives studied by
Brunner et al. ${ }^{11}$ Since the underlying pathophysiology of renal dysfunction in hypertension is not comparable to that of congestive heart failure, it is difficult to relate these results to ours. Proteinuria and an immune complex glomerulopathy have also been reported in hypertensive patients with captopril, ${ }^{12} 13$ but these findings are probably not pertinent to the type of responses we have found in our group of patients with congestive heart failure.

It is worth while to look at individual responses of the patients in our study to see if certain types of patients are more likely to have an adverse renal response to captopril. Fig. 1 shows the change in creatinine clearance during captopril in relation to the initial baseline plasma renin activity. It can readily be seen that the patients who had the greatest decrease in creatinine clearance during captopril were the ones with the higher baseline plasma renin activities. From Fig. 2 and 3 it is apparent that those patients with lower blood pressures during captopril were more likely to have a significant decrease in creatinine clearance and sodium excretion.

These correlations raise the question of what mechanism might underlie the changes in renal function which occurred. It is tempting to postulate that the lower perfusion pressure during captopril resulted in decreased blood flow to the kidney and exacerbated a "pre-renal azotaemia". We did not measure para-amino-hippurate clearance so we cannot support this hypothesis with any direct data on blood flow. Since we did not use invasive haemodynamic monitoring during this study, we do not know what specific responses each patient had in terms of cardiac output and left ventricular filling pressure. In the light of previous studies, however, it is likely that there was an increase in cardiac output and a decrease in pulmonary wedge pressure.

In addition to the changes in renal perfusion pressure, several other factors must be considered.

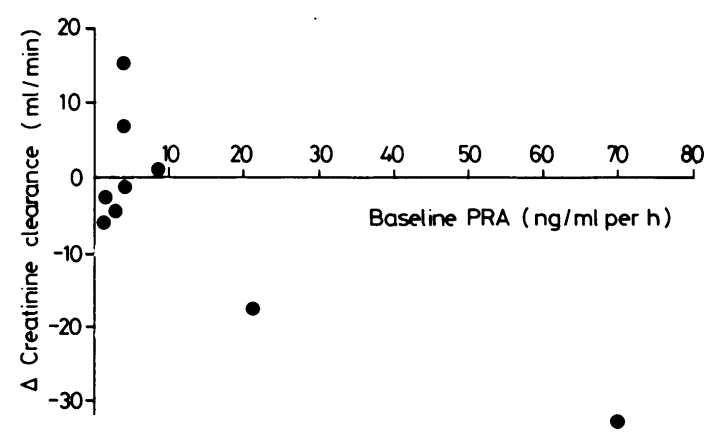

Fig. 1 Relation between the change in creatinine clearance that occurred with captopril, and the baseline plasma renin activity (PRA). 


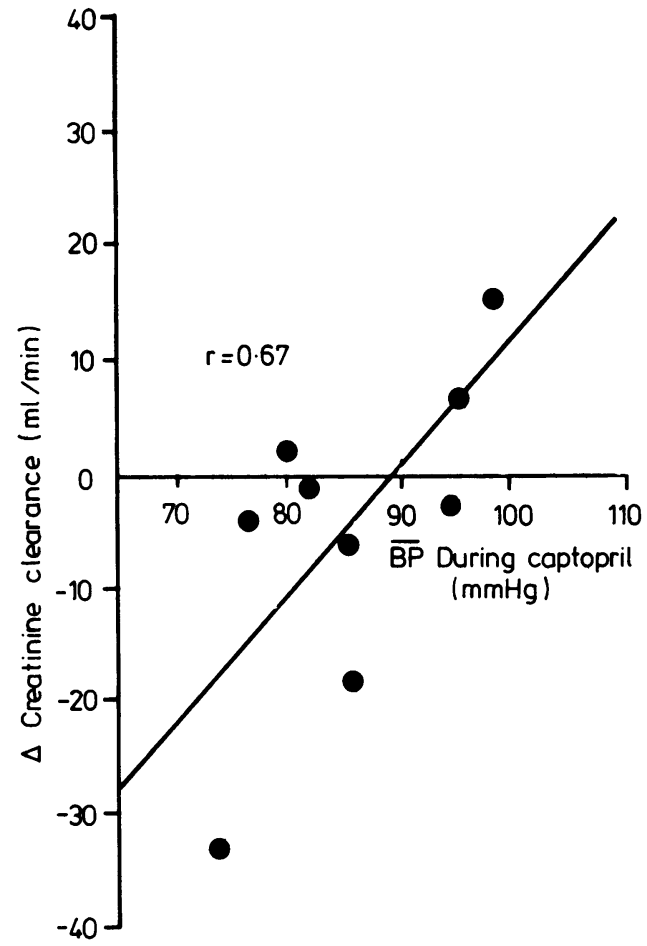

Fig. 2 Correlation between the change in creatinine clearance that occurred with captopril, and the mean blood pressure $(B P)$ obtained during captopril therapy.

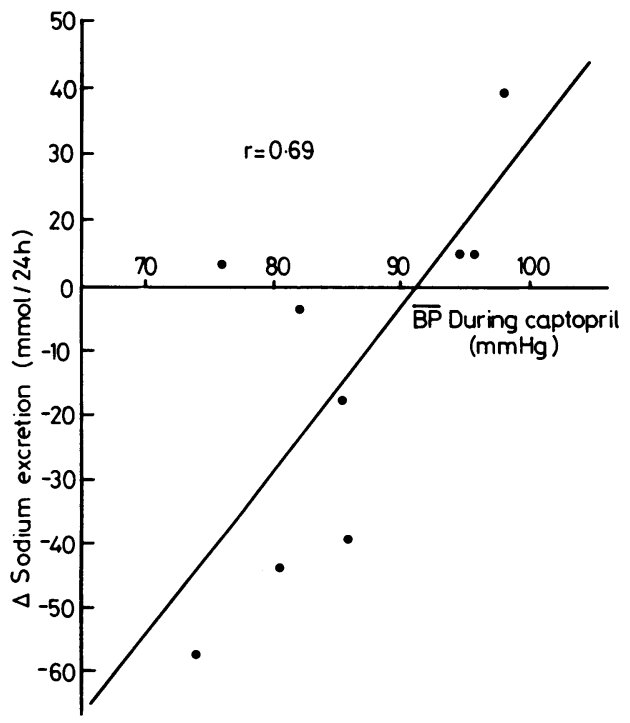

Fig. 3 Correlation between the change in sodium excretion that occurred with captopril and the mean blood pressure $(B P)$ obtained during captopril treatment.
Angiotensin helps regulate aldosterone secretion, and a captopril induced decrease in angiotensin II would decrease aldosterone and promote natriuresis. The direct renal effects of angiotensin II could be beneficial or detrimental depending on the levels obtained. Finally, the baseline volume and electrolyte status, and concomitant treatment (especially with diuretics), can in part determine subsequent responses of the renin-angiotensin system in patients with congestive heart failure. ${ }^{14}$ Thus, considering the multiple control mechanisms involved, some promoting sodium retention and others natriuresis, the response of an individual patient to captopril would be difficult to predict.

The single patient in our study who became symptomatically hypotensive with captopril did so with a dose of $25 \mathrm{mg}$. He had previously received $50 \mathrm{mg}$ captopril under haemodynamic monitoring in a separate study and had only a moderate decrease in blood pressure and an increase in cardiac output. Ader $e t a l .{ }^{4}$ noted a similar response in two of their patients with congestive heart failure given captopril, that is "profound bradycardia and hypotension" after the first $25 \mathrm{mg}$ dose, but with larger doses "the hypotension and bradycardia were much less severe". This suggests an unusual dose response curve for this drug in some patients, and raises the possibility that it may have dose dependent effects not related to its action on the renin angiotensin system.

We have shown that captopril may adversely alter renal function in some patients with congestive heart failure. Creatinine clearance is more likely to decrease in patients with high baseline plasma renin activity and in whom a lower blood pressure occurs during captopril. Thus, patients should be followed closely with serial determinations of indices of renal function and electrolyte balance when captopril is used to treat congestive heart failure. This was a short term investigation (three days of captopril), and a much longer controlled clinical trial is justified to determine better the more chronic effects of captopril in patients with heart failure.

\section{References}

1 Curtiss C, Cohn JN, Vrobel T, Franciosa JA. Role of the renin-angiotensin system in the systemic vasoconstriction of chronic congestive heart failure. Circulation 1978; 58: 763-70.

2 Gavras H, Faxon DP, Berkoben J, Brunner HR, Ryan TJ. Angiotensin converting enzyme inhibition in patients with congestive heart failure. Circulation 1978; 58: $770-6$.

3 Faxon DP, Creager MA, Halperin JL, Gavras H, Coffman JD, Ryan TJ. Central and peripheral hemody- 
namic effects of angiotensin inhibition in patients with refractory congestive heart failure. Circulation 1980; 61: 925-30.

4 Ader R, Chatterjee K, Ports T, Brundage B, Hiramatsu $B$, Parmley $W$. Immediate and sustained hemodynamic and clinical improvement in chronic heart failure by an oral angiotensin-converting enzyme inhibitor. Circulation 1980; 61: 931-7.

5 Dzau VJ, Colucci WS, Williams GH, Curfman G, Meggs L, Hollenberg NK. Sustained effectiveness of converting-enzyme inhibition in patients with severe congestive heart failure. $N$ Engl f Med 1980; 302: 1373-9.

6 Maslowski AH, Nicholls MG, Ikram H, Espiner EA. Haemodynamic, hormonal, and electrolyte responses to captopril in resistant heart failure. Lancet 1981; i: 71-4.

7 Sharpe DN, Coxon RJ, Douglas JE, Long B. Low-dose captopril in chronic heart failure: acute haemodynamic effects and long-term treatment. Lancet 1980; ii: 1154-7.

8 Hollenberg NK, Swartz SL, Passan DR, Williams GH. Increased glomerular filtration rate after convertingenzyme inhibition in essential hypertension. $N$ Engl F Med 1979; 301: 9-12.

9 Atlas SA, Case DB, Sealey JE, Laragh JH, McKinstry DN. Interruption of the renin-angiotensin system in hypertensive patients by captopril induces sustained reduction in aldosterone secretion, potassium retention and natriuresis. Hypertension 1979; 1: 274-80.
10 Atkinson AB, Morton JJ, Brown JJ, et al. Captopril in clinical hypertension. Changes in components of reninangiotensin system and in body composition in relation to fall in blood pressure with a note on measurement of angiotensin II during converting enzyme inhibition. $\mathrm{Br}$ Heart f 1980; 44: 290-6.

11 Brunner HR, Gavras H, Waeber B, et al. Oral angiotensin-converting enzyme inhibitor in long-term treatment of hypertensive patients. Ann Intern Med 1979; 90: 19-23.

12 Case DB, Atlas SA, Mouradian JA, Fishman RA, Sherman RL, Laragh JH. Proteinuria during long-term captopril therapy. $\mathcal{F} A M A$ 1980; 244: 346-9.

13 Hoorntje SJ, Kallenberg CGM, Weening JJ, Donker AJM, The TH, Hoedemaeker PH. Immune-complex glomerulopathy in patients treated with captopril. Lancet 1980; i: $1212-5$.

14 Brown JJ, Davies DL, Johnson VW, Lever AF, Robertson JIS. Renin relationships in congestive cardiac failure, treated and untreated. Am Heart $\mathcal{F}$ 1970; 80: $329-42$.

Requests for reprints to Dr Gordon L Pierpont, VA Medical Center, Cardiovsascular Section (111C), 54th Street and 48th Avenue South, Minneapolis, Minnesota 55417, USA. 